\title{
Eficiência e sustentabilidade: uma análise econômica, social, ambiental e sustentável das usinas paulistas de cana-de-açúcar
}

\author{
Efficiency and sustainability: an economic, social, environmental and \\ sustainable analysis of sugar cane mills in São Paulo
}

Gabriel Malta Campos Dotta e Silva ${ }^{1}$, Ana Elisa Périco² (1)

${ }^{1}$ Faculdade de Ciências e Letras, Universidade Estadual Paulista (UNESP), Araraquara (SP), Brasil. E-mail: gabriel.m.silva@unesp.br. ${ }^{2}$ Faculdade de Ciências e Letras, Programa de Pós-Graduação em Economia, Universidade Estadual Paulista (UNESP), Araraquara (SP), Brasil. E-mail: ana.perico@unesp.br

\begin{abstract}
Como citar: Silva, G. M. C. D., Périco, A. E. (2022). Eficiência e sustentabilidade: uma análise econômica, social, ambiental e sustentável das usinas paulistas de cana de açúcar. Revista de Economia e Sociologia Rural, 60(3), e238512. https://doi.org/10.1590/1806-9479.2021.238512
\end{abstract}

Resumo: Com a recente transformação da economia capitalista, a preocupação com as questões ambientais das atividades econômicas têm sido elemento chave na manutenção da relação competitividadesustentabilidade. No que tange à economia brasileira, observa-se heterogeneidade nas eficiências das cadeias produtivas, devido às características legais e políticas existentes no país. O setor sucroenergético brasileiro, presente e com forte influência na economia desde períodos coloniais, além de ser pioneiro na substituição do uso de recursos fósseis por meios renováveis, constitui um campo marcado por diferenças produtivas significantes. Nesse contexto, o objetivo do artigo é analisar a eficiência das usinas de cana-deaçúcar do estado de São Paulo, no período de 2007 a 2016, sob as óticas econômica, social, ambiental e sustentável, via metodologia de Análise Envoltória de Dados (DEA), gerando modelos de eficiência robustos e completos. Foi observado que as usinas de grande porte possuem alta eficiência econômica, devido a economias de escala, além de que as usinas de porte pequeno obtiveram alto ranqueamento nas óticas social e ambiental, demonstrando que não há necessariamente viés de grandeza operacional nessas análises. Por fim, nota-se a preponderância de usinas sustentáveis benchmarks para as unidades de portes grande e pequeno, conjuntamente com o perfil etanol.

Palavras-chave: setor sucroenergético, eficiência, análise envoltória de dados, sustentabilidade.

\begin{abstract}
Concerns regarding environmental footprint have been the key in sustaining the relationship between competitiveness and sustainability in a changing capitalist context. Brazil has a solid level of heterogeneity in the efficiency of its production chains due to its legal and political characteristics. The Brazilian sugar-energy sector poses a strong influence on the economy, it is the pioneer in replacing the use of fossil fuels for renewable sources, and it is a sector marked by chain efficiency differences. In this context, this study aims to analyze the efficiency of the sugar cane mills in the state of Sao Paulo, from 2007 to 2016, from an economic, social, environmental, and sustainable point of view. Data Envelopment Analysis (DEA) is used to generate robust and complete efficiency models. Large-classified plants were ranked with economic efficiency, due to economies of scale, and small-classified plants ranked benchmarks in the social and environmental analysis, showing that the operational size bias is not necessarily a prerequisite to rank benchmark units. Finally, it was seen a preponderance of small and large-classified mill plants, along with ethanol-classified plants, in the sustainable benchmark ranking.
\end{abstract}

Keywords: sugarcane sector, efficiency, data envelopment analysis, sustainability.

\section{Introdução}

Nas últimas décadas, o capitalismo tem se transformado e cada vez mais se nota maior preocupação em relação aos seus impactos no meio ambiente. $O$ aumento da competitividade e a busca pelo crescimento econômico sustentável têm se tornado as principais engrenagens para tal mudança. Hassini et al. (2012) afirmam que, nos últimos anos, há uma crescente 
onda de investigação que busca o melhor entendimento dos pilares da sustentabilidade em cadeia de produção, tanto de entidades privadas quanto públicas, baseados em medidas de performance produtiva.

Nesse sentido, cabe mencionar que a posição da economia brasileira, em termos de eficácia nas cadeias produtivas, apresenta uma heterogeneidade significativa (Steingraber \& Gonçalves, 2013). Podem-se apontar como possíveis responsáveis por tal condição o pequeno investimento em setores de pesquisa e desenvolvimento (P\&D), dificuldades de acesso ao crédito para empreendedores e empresas, a complexidade tributária e a instabilidade política dos últimos anos.

Em vistas a essa tendência do sistema de produção e do crescente foco na sustentabilidade ${ }^{1}$, em 2004, o Governo Federal lançou o Programa Nacional de Educação Ambiental (ProNEA), orquestrado e dirigido pelo Ministério do Meio Ambiente. O objetivo do programa tem sido assegurar a integração equilibrada das múltiplas dimensões da sustentabilidade (ambiental, social, econômica, política, ética e cultural) ao desenvolvimento da economia brasileira. Conquanto, mesmo com políticas públicas voltadas para o acesso a informações referentes ao aperfeiçoamento do sistema produtivo, é possível identificar grandes lacunas.

Atualmente, um desses hiatos relevantes encontra-se relacionado à gestão produtiva do setor usineiro sucroalcooleiro. Sob o aumento da preocupação global para com o uso sustentável e eficiente das cadeias produtivas - a fim de não causarem danos permanentes para gerações futuras - observa-se um gargalo de pesquisas referentes à eficiência produtiva-sustentável do setor sucroenergético, pioneiro na substituição do uso de recursos fósseis para o uso de meios renováveis.

O Brasil possui, desde tempos coloniais, certa aptidão para o plantio da cana-de-açúcar. Segundo dados do Ministério de Agricultura, Pecuária e Abastecimento (Brasil, 2018), a produção brasileira totalizou 662.473.271 toneladas, mais do que o dobro da produção indiana de 309.998.000 toneladas, na safra de 2016/2017.

Nesse contexto, o objetivo dessa pesquisa foi analisar a eficiência das usinas de cana-de-açúcar do estado de São Paulo, no período de 2007 a 2016, sob as óticas econômica, social, ambiental e sustentável, gerando modelos de eficiência robustos e completos. A partir dessas considerações, é possível observar uma oportunidade de pesquisa, já que, como mencionado, estudos de eficiência em usinas, considerando também variáveis que incorporem aspectos de sustentabilidade (sociais, ambientais e econômicos), não estão ainda difundidos no meio acadêmico. A ausência de pesquisas dessa natureza justifica o desenvolvimento deste estudo.

Este artigo está estruturado da seguinte forma: além desta introdução, a próxima seção mostra a síntese de importantes pesquisas nacionais e internacionais envolvendo a temática de eficiência e sustentabilidade em usinas. A terceira seção apresenta os procedimentos metodológicos utilizados nesta pesquisa, desde a validação dos modelos propostos até as especificações que envolvem a análise envoltória de dados. Na quarta seção constam os principais resultados obtidos a partir dos 4 modelos de eficiência de usinas propostos e, por fim, a última seção apresenta as considerações finais.

\section{Compilação teórica: eficiência e sustentabilidade em usinas de cana-de-açúcar}

A presente seção tem como objetivo apresentar uma breve revisão de literatura com trabalhos relevantes sobre eficiência e sustentabilidade em usinas de cana-de-açúcar, especialmente na

\footnotetext{
1 Reforçado por acordos internacionais, como o Acordo de Paris (2016). Ver http:/www.mma.gov.br/clima/conversaodas-nacoes-unidas/acordes-de-paris
} 
Índia e Brasil, dois dos maiores produtores do mundo. A ideia não é explorar todos os trabalhos já realizados, mas sim alguns considerados relevantes e atuais.

O trabalho de Singh \& Agarwal (2006) examina o crescimento da produtividade total dos fatores (FTP) e seus componentes (mudança de eficiência técnica e mudança de tecnologia) na indústria açucareira da Índia. O crescimento da FTP é estimado aplicando o Índice Malmquist, baseado em modelo DEA-SBM, nos dados em painel de 36 usinas de açúcar para o período 1996-97 a 2002-03. O estudo constata que a FTP média da indústria cresceu a uma taxa moderada de 1,6\% ao ano durante todo o período. A decomposição do crescimento da FTP em mudança de eficiência técnica e mudança tecnológica revela que o crescimento da FTP é principalmente causado pela mudança tecnológica do que pela mudança da eficiência técnica.

Para os autores, a estimativa setorial da FTP atesta que o setor privado apresenta o maior crescimento, seguido pelo setor cooperativo. $O$ padrão regional do crescimento demonstra que as usinas da região oeste alcançaram um crescimento relativamente melhor da FTP do que suas contrapartes nas outras duas regiões. $O$ estudo também constata que as usinas com maior tamanho obtiveram maior crescimento de produtividade do que as menores. Além disso, o crescimento relativamente alto da FTP alcançado durante o período posterior do estudo fornece algumas indicações de que fatores induzidos por políticas, como o licenciamento e a desregulamentação parcial do setor açucareiro, tiveram algum impacto positivo no crescimento da FTP.

A pesquisa de Kumar \& Arora (2012), assim como a de Singh \& Agarwal (2006), analisa a eficiência técnica e de escala na Índia, em termos intertemporais e interestaduais e foi realizada em dois estágios. A delimitação temporal da pesquisa cobriu o período de 1974 a 2005. No primeiro estágio, a análise envoltória de dados (DEA) é usada para obter pontuações de eficiência para os 12 principais estados produtores de açúcar. A regressão truncada em dados em painel foi empregada no segundo estágio para avaliar os principais fatores que explicam as variações observadas nos níveis de eficiência.

Os resultados dos autores (Kumar \& Arora, 2012) sugerem que a ineficiência técnica na indústria açucareira indiana é de cerca de $35,5 \%$ ao ano e decorria, principalmente, da ineficiência gerencial e da ineficiência da escala. Além disso, foi observado um declínio acentuado no nível de eficiência técnica no período pós-reformas, em relação ao nível observado no período pré-reformas. A disponibilidade de mão de obra qualificada e a lucratividade foram os determinantes mais significativos da eficiência técnica na indústria açucareira indiana.

Considerando a realidade brasileira, a pesquisa de Cano \& Tupy (2005) teve como objetivo analisar, por meio da envoltória de dados, a eficiência de 63 usinas do estado de São Paulo, a partir de dados do Anuário da Cana de 2002. O modelo utilizado considerou dois outputs (quantidade de álcool e açúcar produzido) e dois inputs (quantidade de cana utilizada e mão de obra empregada).

Os autores concluem que das 63 usinas analisadas, 22,22\% obtiveram escore máximo, sob ambas óticas (VRS e CRS), e outras 19,04\% obtiveram escore máximo apenas em VRS, sinalizando que estas são eficientes na utilização de insumos, mas têm problemas na escala produtiva.

Em termos relativos (firmas eficientes/firmas total), a macrorregião de Presidente Prudente foi a que apresentou melhor resultado, visto que cerca de $60 \%$ de suas usinas foram consideradas eficientes. A macrorregião de Araçatuba (SP) obteve o pior resultado, com 78\% das unidades produtoras detendo algum tipo de ineficiência, seguida por Piracicaba (SP).

O estudo de Salgado Junior et al. (2009) teve como objetivo analisar o impacto das variáveis tamanho e localização na eficiência operacional de usinas de cana-de-açúcar no Brasil, na safra 2008/2009. Essa pesquisa foi realizada por meio da aplicação da DEA em um universo de 355 usinas. 
Dentre as 355 usinas investigadas, 170 são localizadas no estado de São Paulo e 185 nos demais estados do país. A análise envoltória de dados apontou 11 usinas como eficientes, sendo 8 localizadas em SP e 3 em outros estados. Além disso, dessas 11, cinco usinas eram de grande porte, duas eram de médio porte e quatro usinas de pequeno porte. De forma geral, os resultados sugerem que existe maior concentração de usinas classificadas como eficientes e de tamanho grande, localizadas no estado de São Paulo.

Objetivando uma análise em profundidade, os autores realizaram um estudo de múltiplos casos em um grupo de usinas. Os resultados permitem concluir que a eficiência operacional de usinas de cana-de-açúcar depende da variável tamanho, na medida em que as usinas de maior porte tendem a investir mais em tecnologias que proporcionam maior ganho de eficiência operacional. A eficiência também depende da variável localização, na medida em que o estado de São Paulo apresenta condições climáticas mais favoráveis à extração de uma cana-de-açúcar com maior teor de sacarose, que, consequentemente, pode influenciar na eficiência operacional de usinas de cana-de-açúcar (Salgado Junior et al., 2009).

A pesquisa de Macedo et al. (2010) envolve a importância das questões socioambientais nas usinas, em relação à crescente demanda da sociedade por informações a respeito dos impactos que as atividades empresariais exercem sobre os trabalhadores, a comunidade e o meio ambiente. O objetivo dessa pesquisa foi verificar, por meio da Análise Envoltória de Dados, a relação entre capacidade de investimento e benefícios socioambientais, de forma que, quanto maiores forem os benefícios para uma menor capacidade de investimento, maior será a eficiência e, por conseguinte, o desempenho socioambiental da empresa. A análise foi realizada com 19 usinas, com dados para os anos de 2004, 2005 e 2006.

Os resultados da pesquisa apontam que apenas 15,79\% das usinas analisadas foram eficientes no ano de 2004. Em 2005 e 2006 foram 21,05\% de usinas eficientes. De forma geral, a Agrovale (principal benchmark) apresentou o melhor e a São José Estiva, o menor desempenho socioambiental. Além disso, observou-se uma relação entre desempenho socioambiental e tamanho (medido pela receita), com as maiores empresas tendo desempenhos melhores.

A pesquisa de Brunozi Junior et al. (2012) volta a destacar a importância das usinas paulistas que, embora sejam grandes protagonistas em âmbito nacional, passaram a sofrer concorrência de usinas de outras partes do país. Nesse sentido, os autores identificam maiores esforços das usinas paulistas na melhor gestão de suas atividades como forma de garantir sua importância. Com base nestes aspectos, o objetivo deste estudo consistiu em determinar o grau de eficiência técnica e produtiva das usinas de cana-de-açúcar do estado de São Paulo, analisando concomitantemente o seu desempenho econômico e financeiro.

No estudo (Brunozi Junior et al., 2012) foram analisados o desempenho de 17 usinas paulistas e, para a sua mensuração, foi utilizada a análise envoltória de dados em um modelo composto de três insumos (estoques, imobilizado e salários) e um produto (faturamento bruto). As médias de eficiência técnica e de eficiência de escala foram de $75,1 \%$ e $85 \%$, respectivamente. Tais dados refletem que as usinas ineficientes poderiam reduzir, em média, $24,9 \%$ no uso de insumos sem que o faturamento sofresse retração, assim como se as usinas ineficientes tivessem operado na escala ótima de produção, obteriam a mesma quantidade de produto - nesse caso, faturamento - gastando $15 \%$ a menos de insumos.

A pesquisa de Pereira \& Silveira (2016), por sua vez, analisou a produtividade total dos fatores (PTF) e seus componentes para 17 usinas da região Centro-Sul do Brasil durante o período 2001-2008. A Análise Envoltória de Dados foi utilizada, juntamente com Índice de Malmquist, que avalia os índices de produtividade ao longo do tempo, decompondo-os em índices que captam variação da eficiência técnica e mudanças tecnológicas.

Durante o recorte temporal da pesquisa, a produção de etanol do grupo analisado cresceu 84\%, enquanto que a produção de açúcar aumentou em $43 \%$. Além disso, na análise de produtividade 
do trabalho, foi verificado um aumento de $17 \%$ durante o período analisado. Para os autores (Pereira \& Silveira, 2016), este incremento na produtividade por trabalhador deveu-se a maiores e melhores investimentos no processo produtivo, otimizando o uso da mão de obra.

Em relação ao índice de produtividade DEA-Malmquist, foi possível observar uma variação média anual negativa de $0,2 \%$ e redução ao longo dos anos da pesquisa. Uma possível explicação para tal é que em 2003/2004 houve deslocamento na fronteira de eficiência para um valor maior que 1 na componente mudança técnica, ao passo que a componente eficiência técnica apresentou crescimento negativo. Em outras palavras, as usinas em 2003/2004 não alcançaram a fronteira, resultando em um valor médio final da PTF menor que 1. Em 2006/2007, houve novamente redução da PTF.

Para os autores, outro possível fator de influência para a queda em 2003/2004 pode ser o bom nível alcançado pela amostra em 2003, que combinou um aumento de 13,2\% na moagem de cana e 13\% na produção final. Esse bom desempenho fez reduzir o índice PTF no ano seguinte, pois o incremento na moagem foi menor que 5\%, com redução no volume de etanol produzido, o que pode ser explicado pelas variações de preços da commodityna safra.

Entre as usinas analisadas, a que obteve o melhor desempenho, em termos de crescimento médio da PTF, teve um crescimento médio anual (em termos de PTF) de $2,8 \%$, enquanto que a usina com pior desempenho teve retração média anual de 4,1\%.

Por fim, o estudo de Goldemberg et al. (2008), que trabalhou as questões socioambientais, teve como objetivo apresentar aspectos positivos e negativos da produção de etanol a partir da cana-de-açúcar, principalmente no estado de São Paulo, onde mais de $60 \%$ das plantações de cana do Brasil estão localizadas e são responsáveis por $62 \%$ da produção de etanol. A rápida expansão da produção de etanol a partir da cana-de-açúcar no Brasil levantou várias questões sobre suas consequências negativas e sobre questões de sustentabilidade.

Para os autores, os impactos positivos são a eliminação de compostos de chumbo da gasolina e a redução de emissões nocivas. Há, também, a redução das emissões de $\mathrm{CO}_{2}$, uma vez que o etanol de cana requer apenas uma pequena quantidade de combustíveis fósseis para sua produção, sendo, portanto, um combustível renovável. Esses impactos positivos são particularmente visíveis na melhoria da qualidade do ar nas áreas metropolitanas, mas também nas áreas rurais onde está sendo introduzida a colheita mecanizada de cana verde, eliminando a queima da cana-de-açúcar.

Impactos negativos, como a futura produção em larga escala de etanol a partir da cana-deaçúcar, podem levar à destruição ou danos em áreas de alta biodiversidade, desmatamento, degradação ou danos aos solos por meio do uso de produtos químicos e descarbonização do solo, contaminação ou esgotamento dos recursos hídricos, competição entre produção de alimentos e combustíveis, diminuição da segurança alimentar e agravamento das condições de trabalho nos campos (Goldemberg et al., 2008).

\section{Método de pesquisa}

Para alcançar o objetivo de pesquisa foram definidos, previamente, alguns passos e estratégias, constituindo o método da pesquisa. A técnica utilizada neste trabalho foi a DEA. Dessa maneira, todas as etapas propostas nessa seção estão em função dela.

A proposta inicial de delimitação temporal dessa pesquisa contempla o período de 2007 a 2016, período mais recente e com disponibilidade de dados padronizados.

\subsection{Quantidade de usinas a serem analisadas e variáveis propostas}

A amostra desta pesquisa foi definida a partir da identificação de 15 usinas de açúcar e etanol instaladas no estado de São Paulo, em operação em todos os anos da análise, respeitando o critério de associação à União da Indústria de Cana-de-Açúcar (Única). 
No presente trabalho, cada usina, em cada ano investigado, foi tratada como uma unidade. Assim, por exemplo, a usina "X", no período de 2007 a 2016, gerou 10 unidades virtuais e o mesmo ocorreu para todas as demais. Com isso, o total de unidades investigadas correspondeu a 150. O quadro 1 apresenta a lista de usinas que foram analisadas.

Quadro 1 - Usinas analisadas

\begin{tabular}{|c|c|c|c|c|}
\hline Alta Mogiana & Da Pedra & Ferrari & Nardini & São Martinho \\
\hline Batatais & Diana & Iracema & Santa Maria & Unialco \\
\hline Colombo & Ester & Moreno & São Manuel & Vista Alegre \\
\hline
\end{tabular}

A pesquisa foi realizada a partir de 4 modelos de eficiência. Os três modelos iniciais contemplaram, individualmente, os três pilares da sustentabilidade (econômico, ambiental e social). O quarto modelo compilou os três modelos anteriores em apenas um, o sustentável.

Todos os modelos tiveram variáveis comuns de input, que refletiam, de alguma maneira, os fatores de produção tradicionais. Grande parte das pesquisas já realizadas utilizou, principalmente, as seguintes variáveis como inputs: (i) quantidade de funcionários: administrativo, agrícola e industrial; (ii) área plantada (hectares).

No que diz respeito às variáveis de output, são elas que diferenciam os modelos. Para o modelo econômico, a literatura apresenta as seguintes variáveis de outputs como possibilidades: produção de etanol ( $\mathrm{m}^{3}$ ) e produção de açúcar (ton). Tais dados estão disponíveis nos Anuários da Cana.

Para o modelo ambiental, a literatura aponta uma variável como possibilidade: a emissão de $\mathrm{CO}_{2}$. A obtenção desse dado envolveu alguns cuidados. Cada uma das 15 usinas paulistas investigadas está localizada em cidade distinta das outras usinas. Além disso, a seleção das unidades respeitou a condição daquela usina ser a única no município. O Projeto Canasat disponibiliza a área colhida total, por município, desagregando-a em área colhida crua e área colhida com queima. Uma vez averiguado que toda a área colhida da cidade pertence à única usina lá instalada, a partir da metodologia de Figueiredo \& Scala (2011), tornou-se possível o cálculo da emissão de $\mathrm{CO}_{2}$ para cada usina analisada.

Os estudos de Figueiredo \& Scala (2011) indicam que as emissões oriundas da colheita com uso da queimada são de $3.104 \mathrm{~kg}$ de $\mathrm{CO}_{2 e q} h a^{-1} y^{-1}$, enquanto as emissões decorrentes da colheita de cana crua são de $1.620 \mathrm{~kg}$ de $\mathrm{CO}_{2 e q} \mathrm{ha}^{-1} y^{-1}$, considerando o balanço de emissões decorrentes das atividades agrícolas. Logo, tornou-se possível estimar a quantidade de $\mathrm{CO}_{2 e q}$ proveniente das áreas de cana-de-açúcar das usinas analisadas, tanto com emprego da queimada quanto sem uso do fogo, por unidade-ano. A equação 1, apresentada a seguir, representa essa variável:

$$
\operatorname{ECO}_{j}^{i}=\left(A q_{j}^{i} \times 3,104\right)+\left(A c_{j}^{i} \times 1,620\right)
$$

Em que:

$E C O 2_{j}^{i}$ é o valor das emissões de $\mathrm{CO}_{2 e q}$ provenientes do processo de colheita da cana-de-açúcar no ano $i$ pela unidade $j$.

$A q_{j}^{i}$ corresponde à área colhida de cana-de-açúcar, em hectares, com uso da queimada no ano $i$ pela unidade $j$.

$A c_{j}^{i}$ corresponde à área colhida de cana-de-açúcar, em hectares, sem uso da queimada no ano $i$ pela unidade $j$. 
Ademais, deve-se ressaltar que a variável calculada é classificada como variável indesejada, pois espera-se que as emissões de $\mathrm{CO}_{2 e q}$ sejam do tipo "quanto menor, melhor". Logo, foi utilizada a metodologia de Seiford \& Zhu (2002), de transformação monotônica decrescente, na qual valores dos outputs indesejados são transformados no inverso do seu valor. Logo, a variável emissão de $\mathrm{CO}_{2 e q}$ será minimizada ao invés de ser maximizada.

Ressalta-se, ainda, que, para os modelos ambiental e sustentável, os dados do projeto Canasat estavam disponíveis até o período de 2013. Sendo assim, estes modelos foram rodados para o período de 2007 a 2013. Para a análise envoltória de dados, foi utilizado o inverso da variável de emissão de $\mathrm{CO}_{2}$, nos dois modelos, já que ela é do tipo quanto menor, melhor.

Para o modelo social, a partir de adaptação do trabalho de Zambianco (2018), a proposta seria utilizar a variável salário médio. Esperava-se que as usinas investigadas fornecessem esses dados anuais para todo o horizonte da pesquisa, por meio de websurveys. No entanto, como isso não ocorreu, a estratégia foi buscar a RAIS (Relação Anual de Informações Sociais), fornecida pelo Ministério da Economia (Brasil, 2019), e identificar o salário médio recebido pelas pessoas empregadas na atividade de cultivo de cana-de-açúcar, anualmente, em cada município. Para tanto, foi necessário adotar o pressuposto de que essas pessoas que trabalhavam com cana-de-açúcar em determinada cidade estavam relacionadas, direta ou indiretamente, à única usina lá instalada.

Como essa variável foi a única mensurada em unidade monetária e considerando que todas as usinas, em diferentes anos, foram analisadas conjuntamente, foi necessário realizar a transformação dos salários médios nominais em salários médios reais. O indexador utilizado foi o INPC e os valores utilizados são correntes de 2007.

Por fim, para o modelo sustentável, o quadro 2 apresenta maior detalhamento das variáveis utilizadas.

Quadro 2 - Caracterização das variáveis

\begin{tabular}{|c|c|c|}
\hline \multicolumn{2}{|c|}{ Variável } & Tipo \\
\hline Área plantada & Input & Anuário da Cana, publicação da editora ProCana \\
\hline Funcionários & Input & Anuário da Cana, publicação da editora ProCana \\
\hline Produção de etanol & Output & Anuário da Cana, publicação da editora ProCana \\
\hline Produção de açúcar & Output & Anuário da Cana, publicação da editora ProCana \\
\hline Emissão de $\mathrm{CO}_{2}$ & Output & Projeto Canasat, do INPE \\
\hline Salário médio & Output & RAIS, do ME \\
\hline
\end{tabular}

\subsection{Validação das variáveis}

Na literatura especializada em DEA, há menção de alguns métodos disponíveis para a validação de variáveis e, consequentemente, dos modelos de eficiência propostos. Para fins desta pesquisa, a Análise de Componentes Principais aplicada à DEA (PCA-DEA) foi utilizada. A PCA-DEA, proposta por Adler \& Golany (2001), busca reduzir a extensão de um conjunto de dados a partir da combinação dos dados originais. Tal técnica é considerada robusta pela comunidade acadêmica, uma vez que preserva parte das variáveis originais.

O método PCA-DEA é amplamente utilizado em pesquisas internacionais e, na comparação com outros métodos, apresenta resultados robustos e precisos (Adler \& Yazhemsky, 2010). Nataraja \& Johnson (2011) compararam diversos métodos de seleção de variáveis e seus resultados corroboram as conclusões de Adler \& Yazhemsky (2010) e ressaltam, ainda, que o método PCA-DEA apresenta menor tempo de execução e funciona melhor que os demais métodos quando as amostras são de tamanho pequeno a médio (abaixo de 300). 
Na PCA-DEA alguns pontos são relevantes no sentido de definir pela permanência ou não de variáveis nos modelos propostos, sendo eles: as comunalidades, a matriz de correlação anti-imagem, os testes de Kaiser, Meyer, Olkin (KMO) e Bartlett e os autovalores.

As comunalidades indicam a proporção da variância explicada pelas componentes principais. Existem tantas comunalidades quantas são as variáveis do modelo e os valores podem variar entre 0 e 1 , sendo 0 quando os fatores não explicam nenhuma variância da variável e 1 quando explicam a sua totalidade. Valores abaixo de 0,5 sugerem a exclusão da variável.

A matriz de correlação anti-imagem indica a adequação de cada variável para ser usada na PCA-DEA. Em casos de se detectarem valores pequenos na diagonal $(r<0,4)$, deve considerar-se a eliminação da variável.

O teste KMO é uma medida da adequação dos dados das variáveis para entrarem no modelo e testa se o método é adequado aos dados disponíveis. Trata-se de um teste que varia de 0 a 1 , sendo que valores abaixo de 0,4 invalidam o método ou não classificam os dados como adequados para o método proposto.

O teste de Bartlett é baseado na distribuição estatística de qui-quadrado e testa a hipótese nula de que a matriz de correlação é uma matriz identidade, isto é, não há correlação entre as variáveis. Valores de significância maiores do que 0,1 indicam que os dados não são adequados para o tratamento com o método PCA-DEA. Por sua vez, valores menores permitem rejeitar a hipótese nula. Por fim, os autovalores apontam o percentual acumulado da variância que os fatores são capazes de explicar.

\subsection{Modelo a ser utilizado}

Para definir o modelo que representa melhor a tecnologia de produção, há necessidade de fazer algumas opções em relação à sua orientação e quanto ao tipo de retorno de escala.

No caso específico deste trabalho, considerou-se desfavorável a utilização do modelo com orientação para o input, pois não se almeja reduzir os recursos das unidades analisadas (funcionários e área). A meta foi aumentar os outputs, a partir dos níveis de inputs observados. Com isso, a escolha se deu pelo modelo DEA com orientação para o output.

Em relação ao modelo selecionado, CCR (retorno constante de escala) ou BCC (retorno variável de escala), é importante que sejam calculados os escores de eficiência considerando os dois modelos. Nesse sentido, Banker et al. (1996) sugere a realização do teste de Kolmogorov-Smirnov (KS) para a seleção entre um dos dois modelos, uma vez que a escolha da tecnologia é uma questão crucial e, se feita de forma arbitrária, pode produzir resultados viesados. A estatística deste teste é dada por (Equação 2):

$T S M=\max \left\{F\left(\theta_{D E A} C C R\right), F\left(\theta_{D E A} B C C\right)\right\}$

(Equação 2)

Em que $F\left(\theta_{D E A C C R}\right)$ e $F\left(\theta_{D E A B C C}\right)$ são as distribuições de ineficiência acumuladas dos modelos DEA-CCR e DEA-BCC. No procedimento do teste, a estatística TSM é comparada com o valor crítico de D obtido. Se, $\mathrm{T}_{\mathrm{SM}}<\mathrm{D}$ crítico, aceita-se $\mathrm{H}_{0}$; se, TSM $>\mathrm{D}$ crítico, rejeita-se $\mathrm{H}_{0}$ e aceita-se $\mathrm{H}_{1}$. Onde $\mathrm{H}_{0}$ determina a aceitação do modelo de retornos constantes de escala (CCR) e $\mathrm{H}_{1}$ indica a aceitação do modelo de retornos variáveis de escala (BCC).

O teste KS foi realizado e o modelo BCC selecionado como o mais adequado. Tal procedimento está devidamente detalhado na seção 4.2. O modelo proposto, BCC com orientação para o output (Banker et al., 1984), é apresentado a seguir (Equação 3): 
Maximizar $\sum_{i=1}^{n} v_{i} x_{k i}+v_{k}$

Sujeito a:

$\sum_{r=1}^{m} u_{r} y_{r k}=1$

$\sum_{r=1}^{m} u_{r} y_{j r}-\sum_{i=1}^{n} v_{i} x_{j r}-v_{k} \geq 0$

$u_{r}, v_{i} \geq 0$

Considerando: $\mathrm{y}=$ outputs; $\mathrm{x}=$ inputs $/ \mathrm{u}, \mathrm{v}=$ pesos $/ \mathrm{r}=1, \ldots, \mathrm{m} . ; \mathrm{i}=1, \ldots, \mathrm{n} ; \mathrm{j}=1, \ldots, \mathrm{n}$.

\section{Resultados e discussões}

Esta seção tem por objetivo apresentar os resultados obtidos tanto da validação dos modelos propostos, retornos de escala, como da Análise Envoltória de Dados.

\subsection{Validação dos modelos}

Em relação às comunalidades, conforme a tabela 1, para os modelos econômico, social e sustentável, todas as variáveis podem ser mantidas, uma vez que valores abaixo de 0,5 sugerem que os fatores comuns explicam a variância da variável. No modelo ambiental, parece aceitável o resultado obtido, tendo em conta que a quantidade de funcionários pouco explica da variância dos demais componentes.

Tabela 1 - Comunalidades

\begin{tabular}{|c|c|c|c|c|c|c|c|c|}
\hline & \multicolumn{2}{|c|}{ Econômico } & \multicolumn{2}{|c|}{ Ambiental } & \multicolumn{2}{|c|}{ Social } & \multicolumn{2}{|c|}{ Sustentável } \\
\hline & Inicial & Extração & Inicial & Extração & Inicial & Extração & Inicial & Extração \\
\hline Área plantada & 1,000 & ,740 & 1,000 & ,952 & 1,000 & ,763 & 1,000 & ,947 \\
\hline Funcionários & 1,000 &, 587 & 1,000 & 140 & 1,000 & ,714 & 1,000 & ,526 \\
\hline $\begin{array}{l}\text { Produção de } \\
\text { açúcar }\end{array}$ & 1,000 & ,590 & - & - & - & - & 1,000 & 951 \\
\hline $\begin{array}{l}\text { Produção de } \\
\text { etanol }\end{array}$ & 1,000 & 640 & - & - & - & - & 1,000 & ,630 \\
\hline $\mathrm{CO}_{2}$ & - & - & 1,000 & 938 & - & - & 1,000 & ,640 \\
\hline Salário & - & - & - & - & 1,000 & 794 & 1,000 &, 504 \\
\hline
\end{tabular}

Fonte: Resultados da pesquisa.

A matriz de correlação anti-imagem indica a adequação de cada variável para ser usada na PCA-DEA. Os valores na diagonal (Tabela 2 ) sugerem a permanência de todas as variáveis em todos os modelos. 
Tabela 2 - Matriz correlação anti-imagem

\begin{tabular}{|c|c|c|c|c|c|c|}
\hline \multicolumn{7}{|c|}{ Modelo Sustentável } \\
\hline & $\begin{array}{c}\text { Área } \\
\text { plantada }\end{array}$ & Funcionários & $\mathrm{CO}_{2}$ & $\begin{array}{l}\text { Prod. } \\
\text { açúcar }\end{array}$ & $\begin{array}{l}\text { Prod. } \\
\text { Etanol }\end{array}$ & Salários \\
\hline Área plantada & ,508 &,- 146 &,- 953 &,- 129 &,- 092 &,- 166 \\
\hline Funcionários &,- 146 & ,666 & ,073 & ,092 & ,123 &,- 173 \\
\hline $\mathrm{CO}_{2}$ &,- 953 & ,073 &, 507 & 123 & ,092 &, 228 \\
\hline Prod. açúcar &,- 129 & ,092 & 123 &, 580 &,- 251 &,- 006 \\
\hline Prod. etanol &,- 092 & 123 & ,092 &,- 251 &, 538 & 193 \\
\hline Salário &,- 166 &,- 173 & ,228 &,- 006 & 193 & 0,502 \\
\hline \multicolumn{7}{|c|}{ Modelo Econômico } \\
\hline & $\begin{array}{c}\text { Área } \\
\text { plantada }\end{array}$ & Funcionários & $\begin{array}{l}\text { Prod. } \\
\text { açúcar }\end{array}$ & $\begin{array}{l}\text { Prod. } \\
\text { etanol }\end{array}$ & & \\
\hline Área plantada &, 551 &,- 176 &,- 024 &,- 057 & & \\
\hline Funcionários &,- 176 &, 550 & ,066 & 183 & & \\
\hline Prod. açúcar &,- 024 & ,066 &, 552 &,- 299 & & \\
\hline Prod. etanol &,- 057 & , 183 &,- 299 &, 532 & & \\
\hline \multicolumn{7}{|c|}{ Modelo Ambiental } \\
\hline & $\begin{array}{c}\text { Área } \\
\text { plantada }\end{array}$ & Funcionários & $\mathrm{CO}_{2}$ & & & \\
\hline Área plantada &, 507 &,- 154 &,- 952 & & & \\
\hline Funcionários &,- 154 & ,710 & ,093 & & & \\
\hline $\mathrm{CO}_{2}$ &,- 952 & ,093 & ,507 & & & \\
\hline \multicolumn{7}{|c|}{ Modelo Social } \\
\hline & $\begin{array}{c}\text { Área } \\
\text { plantada }\end{array}$ & Funcionários & Salário & & & \\
\hline Área plantada & ,546 &,- 181 & 161 & & & \\
\hline Funcionários &,- 181 & ,532 &,- 123 & & & \\
\hline Salário &, 161 &,- 123 & ,518 & & & \\
\hline
\end{tabular}

Fonte: Resultados da pesquisa.

Por meio do teste KMO, apresentado na tabela 3, o valor encontrado permite aferir adequação média entre dados e cada um dos modelos. Por sua vez, o teste de Bartlett indicou que os dados são adequados (nível de significância abaixo de 0,1).

Tabela 3 - Testes KMO e Bartlett

\begin{tabular}{cccccc} 
& & Econômico & Social & Ambiental & Sustentável \\
\multicolumn{2}{c}{$\begin{array}{c}\text { Medida KMO de adequação de } \\
\text { amostragem }\end{array}$} & $\mathbf{6 3 5}$ & $\mathbf{6 3 4}$ & $\mathbf{6 1 3}$ & $\mathbf{6 0 7}$ \\
$\begin{array}{c}\text { Teste de } \\
\text { Qui-quadrado aprox. }\end{array}$ & $\mathbf{2 7 , 2 7 5}$ & 9,329 & $\mathbf{2 5 1 , 0 2 7}$ & $\mathbf{2 7 9 , 1 3 9}$ \\
$\begin{array}{c}\text { esfericidade de } \\
\text { Bartlett }\end{array}$ & Df & 6 & 3 & 3 & 15 \\
\hline
\end{tabular}

Fonte: Resultados da pesquisa.

Na tabela 4 são apresentados os autovalores, o percentual da variância que os fatores são capazes de explicar e o percentual acumulado dessa variância. De forma geral, o modelo econômico teve dois componentes maiores que 1, explicando 63,9\% da variabilidade total; o modelo ambiental, com dois componentes retidos, é capaz de explicar 97,3\% da variabilidade 
total; o modelo social, também com dois valores retidos, explicou 75,7\% da variabilidade total; e o modelo sustentável foi capaz de explicar $59,6 \%$ do total da variabilidade.

Tabela 4 - Variância total explicada (autovalores)

\begin{tabular}{|c|c|c|c|c|c|c|c|}
\hline \multicolumn{8}{|c|}{ Modelo Econômico } \\
\hline \multirow{2}{*}{ Comp. } & \multicolumn{3}{|c|}{ Valores próprios iniciais } & \multicolumn{4}{|c|}{$\begin{array}{c}\text { Somas de extração de carregamentos ao } \\
\text { quadrado }\end{array}$} \\
\hline & Total & $\begin{array}{c}\% \text { de } \\
\text { variância }\end{array}$ & $\begin{array}{c}\% \\
\text { cumulativa }\end{array}$ & Total & \% de variância & $\% \mathrm{cl}$ & umulativa \\
\hline 1 & 1,445 & 36,132 & 36,132 & 1,445 & 36,132 & & 36,132 \\
\hline 2 & 1,111 & 27,772 & 63,904 & 1,111 & 27,772 & & 63,904 \\
\hline 3 & ,784 & 19,611 & 83,515 & & & & \\
\hline 4 & ,659 & 16,485 & 100,000 & & & & \\
\hline \multicolumn{8}{|c|}{ Modelo Social } \\
\hline \multirow{2}{*}{ Comp. } & \multicolumn{3}{|c|}{ Valores próprios iniciais } & \multicolumn{4}{|c|}{$\begin{array}{l}\text { Somas de extração de carregamentos ao } \\
\text { quadrado }\end{array}$} \\
\hline & Total & $\begin{array}{c}\text { \% de } \\
\text { variância }\end{array}$ & $\begin{array}{c}\% \\
\text { cumulativa }\end{array}$ & Total & \% de variância & $\% \mathrm{cl}$ & umulativa \\
\hline 1 & 1,176 & 39,209 & 39,209 & 1,176 & 39,209 & & 39,209 \\
\hline 2 & 1,095 & 36,503 & 75,712 & 1,095 & 36,503 & & 75,712 \\
\hline 3 & ,729 & 24,288 & 100,000 & & & & \\
\hline \multicolumn{8}{|c|}{ Modelo Ambiental } \\
\hline \multirow{2}{*}{ Comp. } & \multicolumn{3}{|c|}{ Valores próprios iniciais } & \multicolumn{4}{|c|}{$\begin{array}{c}\text { Somas de extração de carregamentos ao } \\
\text { quadrado }\end{array}$} \\
\hline & Total & $\begin{array}{c}\text { \% de } \\
\text { variância }\end{array}$ & $\begin{array}{c}\% \\
\text { cumulativa }\end{array}$ & Total & \% de variância & $\% \mathrm{cl}$ & umulativa \\
\hline 1 & 2,030 & 64,657 & 64,657 & 2,030 & 64,657 & & 64,657 \\
\hline 2 & 1,025 & 32,647 & 97,304 & 1,025 & 32,647 & & 97,304 \\
\hline 3 &, 046 & 1,522 & 100,000 & & & & \\
\hline \multicolumn{8}{|c|}{ Modelo Sustentável } \\
\hline \multirow{2}{*}{ Comp. } & \multicolumn{3}{|c|}{ Valores próprios iniciais } & \multicolumn{4}{|c|}{$\begin{array}{l}\text { Somas de extração de carregamentos ao } \\
\text { quadrado }\end{array}$} \\
\hline & Total & $\begin{array}{c}\text { \% de } \\
\text { variância }\end{array}$ & $\begin{array}{c}\% \\
\text { cumulativa }\end{array}$ & Total & $\%$ de v & ncia & $\begin{array}{c}\% \\
\text { cumulativa }\end{array}$ \\
\hline 1 & 2,060 & 34,338 & 34,338 & 2,060 & & & 34,338 \\
\hline 2 & 1,518 & 25,292 & 59,630 & 1,518 & & & 59,630 \\
\hline 3 & ,992 & 16,527 & 76,157 & & & & \\
\hline 4 & ,736 & 12,267 & 88,423 & & & & \\
\hline 5 & ,652 & 10,867 & 99,290 & & & & \\
\hline 6 & ,043 & ,710 & 100,000 & & & & \\
\hline
\end{tabular}

Fonte: Resultados da pesquisa.

A partir desses resultados, todos os modelos inicialmente propostos foram validados.

\subsection{Retornos de escala}

O teste de escala foi realizado para todos os modelos. O valor crítico para os modelos econômico e social é o mesmo, tendo em consideração que o número de observações contempla 
toda a delimitação temporal da pesquisa. Para os modelos ambiental e sustentável, o número de observações é menor, uma vez que os dados de emissão de $\mathrm{CO}_{2}$ estão disponíveis até 2013.

Para o modelo econômico, a partir dos dados agregados (2007-2016) e o valor da estatística $(0,173304)$ comparado com o valor crítico $(n=150, a=5 \%$; dcrítico =0,1110), foi possível aceitar a hipótese de retornos variáveis de escala (BCC). No modelo social, mantidos os valores críticos, e tendo sido encontrado o valor da estatística de 0,186615, aceita-se, também, a hipótese de retornos variáveis de escala.

Os modelos social e sustentável possuem 105 observações. Para o modelo social, tendo em consideração os dados de 2007 a 2013 e o valor da estatística (0,224638) comparado com o valor crítico ( $n=105, a=5 \%$; dcrítico = 0,132722), foi possível aceitar a hipótese de retornos variáveis de escala. Por fim, o modelo sustentável, também com 105 observações, possui estatística de 0,187181 e quando comparada ao valor crítico ( $n=105, a=5 \%$; dcrítico = 0,132722), também corrobora a hipótese de retornos variáveis de escala.

\subsection{Análise Envoltória de Dados}

A presente subseção destina-se à apresentação dos resultados da aplicação da Análise Envoltória de Dados aos dados das 15 usinas de álcool e etanol, investigadas durante 10 anos, em três abordagens: econômica, social e ambiental. As análises baseiam-se na maximização da relação output/ input, em que outputvaria de acordo com a ótica analisada, mantendo sempre os mesmos inputs, como já supracitado no artigo.

\subsubsection{Abordagem econômica}

As usinas sucroenergéticas brasileiras são classificadas em portes de operação, podendo ser (a) grandes; (b) médias e (c) pequenas. As grandes são aquelas que moem mais de 4 milhões de toneladas/ano, as médias moem entre 2,5 e 4 milhões/ano e as pequenas moem menos de 2,5 milhões de toneladas por ano.

Além da classificação por porte, as usinas também possuem perfis estratégicos no âmbito core product, podendo ser de perfil açúcar ou etanol. Posto assim, e partindo da estimativa de conversão de que 1 tonelada de cana-de-açúcar moída transforma-se em (i) 118 quilos de açúcar (Agência Embrapa de Informação Tecnológica, 2006) ou (ii) 90 litros de etanol (Nova Cana, 2012), pode-se obter a fração de destino da cana para os dois produtos.

Ao analisar a média das porcentagens de destinação de cana moída por usina, para o intervalo de tempo da pesquisa, consegue-se estimar o perfil médio da usina analisada. Para tal, usa-se metodologia de maioria simples para determinação: se a média de conversão de cana em etanol, para o tempo determinado, for maior que 50\%, tal unidade terá perfil etanol (e vice-versa). O quadro 3 apresenta, respectivamente, o porte e o perfil das usinas. 
Quadro 3 - Porte e perfil

\begin{tabular}{|c|c|c|c|c|c|}
\hline Usina & Porte & Perfil & Usina & Porte & Perfil \\
\hline São Martinho & \multirow[t]{4}{*}{ Grande } & \multirow[t]{3}{*}{ Açúcar } & Ferrari & \multirow[t]{9}{*}{ Pequeno } & \multirow[t]{5}{*}{ Açúcar } \\
\hline Alta Mogiana & & & Ester & & \\
\hline Colombo & & & Diana & & \\
\hline Da Pedra & & Etanol & Santa Maria & & \\
\hline Iracema & \multirow[t]{5}{*}{ Médio } & \multirow[t]{5}{*}{ Açúcar } & Unialco & & \\
\hline Batatais & & & Vista Alegre & & Etanol \\
\hline Nardini & & & & & \\
\hline São Manuel & & & & & \\
\hline Moreno & & & & & \\
\hline
\end{tabular}

A análise da abordagem econômica baseia-se na maximização da relação output, produção de açúcar (toneladas) e de etanol (metros cúbicos), com os inputs, hectares plantados e número de funcionários, para o ano safra em questão. A tabela 5 apresenta os resultados do modelo econômico.

Tabela 5 - Eficiência econômica das usinas

\begin{tabular}{|c|c|c|c|c|c|c|c|c|c|c|c|}
\hline Usinas & 2007 & 2008 & 2009 & 2010 & 2011 & 2012 & 2013 & 2014 & 2015 & 2016 & Média \\
\hline $\begin{array}{c}\text { Alto } \\
\text { Mogiana }\end{array}$ & $56,1 \%$ & $60,2 \%$ & $67,0 \%$ & $71,3 \%$ & $81,4 \%$ & $69,4 \%$ & $70,8 \%$ & $73,2 \%$ & $75,4 \%$ & $75,9 \%$ & $70,1 \%$ \\
\hline Batatais & $47,0 \%$ & $47,4 \%$ & $49,5 \%$ & $47,6 \%$ & $52,2 \%$ & $47,8 \%$ & $45,9 \%$ & $19,4 \%$ & $58,3 \%$ & $53,5 \%$ & $46,9 \%$ \\
\hline Colombo & $84,9 \%$ & $87,7 \%$ & $88,5 \%$ & $82,1 \%$ & $89,2 \%$ & $80,0 \%$ & $82,9 \%$ & $82,8 \%$ & $78,7 \%$ & $81,6 \%$ & $83,8 \%$ \\
\hline Da Pedra & $95,0 \%$ & $88,5 \%$ & $91,6 \%$ & $81,8 \%$ & $84,4 \%$ & $74,4 \%$ & $80,1 \%$ & $82,7 \%$ & $96,8 \%$ & $87,5 \%$ & $86,3 \%$ \\
\hline Diana & $8,6 \%$ & $10,8 \%$ & $10,3 \%$ & $3,9 \%$ & $6,0 \%$ & $5,8 \%$ & $5,7 \%$ & $13,7 \%$ & $20,0 \%$ & $36,5 \%$ & $12,1 \%$ \\
\hline Ester & $52,9 \%$ & $53,6 \%$ & $56,4 \%$ & $58,3 \%$ & $47,8 \%$ & $48,3 \%$ & $42,4 \%$ & $51,0 \%$ & $53,1 \%$ & $54,3 \%$ & $51,8 \%$ \\
\hline Ferrari & $38,8 \%$ & $50,9 \%$ & $59,2 \%$ & $50,4 \%$ & $69,5 \%$ & $62,4 \%$ & $65,1 \%$ & $73,1 \%$ & $69,9 \%$ & $76,0 \%$ & $61,5 \%$ \\
\hline Iracema & $45,3 \%$ & $66,7 \%$ & $65,2 \%$ & $59,5 \%$ & $59,1 \%$ & $61,1 \%$ & $64,7 \%$ & $68,0 \%$ & $63,9 \%$ & $81,2 \%$ & $63,5 \%$ \\
\hline Moreno & $54,4 \%$ & $41,9 \%$ & $53,5 \%$ & $98,0 \%$ & $56,0 \%$ & $17,0 \%$ & $53,5 \%$ & $52,7 \%$ & $57,6 \%$ & $50,2 \%$ & $53,5 \%$ \\
\hline Nardini & $78,5 \%$ & $85,2 \%$ & $92,4 \%$ & $85,5 \%$ & $85,7 \%$ & $77,6 \%$ & $88,2 \%$ & $91,6 \%$ & $93,2 \%$ & $94,8 \%$ & $87,3 \%$ \\
\hline $\begin{array}{l}\text { Santa } \\
\text { Maria }\end{array}$ & $29,8 \%$ & $32,6 \%$ & $46,3 \%$ & $39,9 \%$ & $32,7 \%$ & $39,0 \%$ & $77,8 \%$ & $77,8 \%$ & $57,2 \%$ & $57,4 \%$ & $49,1 \%$ \\
\hline $\begin{array}{c}\text { São } \\
\text { Manuel }\end{array}$ & $30,9 \%$ & $13,3 \%$ & $49,4 \%$ & $49,6 \%$ & $53,6 \%$ & $50,1 \%$ & $51,8 \%$ & $57,4 \%$ & $55,7 \%$ & $61,2 \%$ & $47,3 \%$ \\
\hline $\begin{array}{c}\text { São } \\
\text { Martinho }\end{array}$ & $99,7 \%$ & $89,1 \%$ & $99,7 \%$ & $93,3 \%$ & $96,8 \%$ & $96,6 \%$ & $92,4 \%$ & $95,5 \%$ & $100,0 \%$ & $99,7 \%$ & $96,3 \%$ \\
\hline Unialco & $13,1 \%$ & $36,8 \%$ & $16,4 \%$ & $13,3 \%$ & $30,7 \%$ & $12,3 \%$ & $35,2 \%$ & $38,3 \%$ & $8,7 \%$ & $26,9 \%$ & $23,2 \%$ \\
\hline Vista Alegre & $5,8 \%$ & $28,2 \%$ & $30,9 \%$ & $16,9 \%$ & $30,8 \%$ & $25,4 \%$ & $27,3 \%$ & $27,1 \%$ & $26,2 \%$ & $26,6 \%$ & $24,5 \%$ \\
\hline \multicolumn{12}{|c|}{ Medidas estatísticas } \\
\hline Máximo & \multirow{2}{*}{\multicolumn{3}{|c|}{$\begin{array}{c}\text { Mínimo } \\
\text { 3,9\% }\end{array}$}} & \multirow{2}{*}{\multicolumn{2}{|c|}{$\begin{array}{l}\text { Média } \\
57,1 \%\end{array}$}} & \multicolumn{3}{|c|}{ Mediana } & & \multicolumn{2}{|c|}{ Desvio-padrão } \\
\hline $100 \%$ & & & & & & & $56,8 \%$ & & & 26, & \\
\hline
\end{tabular}

Fonte: Resultados da pesquisa.

A média geral de eficiência das usinas foi de 57,1\%, com desvio-padrão de 26,3\%. Percebe-se, ainda, que na análise por porte houve uma tendência de maior eficiência e homogeneidade por tamanho, demonstrando que há incidência de economias de escala para o desempenho econômico das usinas analisadas. No entanto, na análise por perfil, não foi possível observar nenhuma tendência, uma vez que houve regularidade de eficiência entre as duas possibilidades de core product. A Usina São Martinho S.A, de porte grande e perfil açúcar, foi a unidade benchmark 
nessa análise, com média de eficiência de 96,3\% (para os anos analisados) corroborando a tendência já explicitada de economias de escala na análise econômica das usinas.

A tabela 6 apresenta os valores médios, do período de 2007 a 2016, de açúcar (em toneladas) e etanol (em metros cúbicos) produzidos por área (em hectare) e da eficiência para cada usina. A variável de input "área plantada" foi selecionada para a análise, apresentada a seguir, por possuir a maior comunalidade no modelo econômico, demonstrada na tabela 1. Ainda assim, é importante resssaltar que, além desse input, também foi utilizado como recurso produtivo, a quantidade de funcionários.

Os dados dos três indicadores apresentados (açúcar/área, etanol/área e eficiência), por usina, foram subdividos em tercis. Para cada um dos indicadores, no primeiro tercil estão agrupados os dados das usinas de pior desempenho, no segundo tercil estão agrupados os dados das usinas de desempenho intermediário e, por fim, no terceiro tercil estão os dados das usinas de melhor desempenho.

Tabela 6 - Relações Output/Input das usinas e indicadores de eficiência

\begin{tabular}{cccc} 
Usina & Açúcar/área & Etanol/área & Eficiência Econômica \\
Nardini & 49,3 & 26,6 & $87,3 \%$ \\
Colombo & 41,2 & 17,3 & $83,8 \%$ \\
São Martinho & 39,9 & 20,7 & $96,3 \%$ \\
Da Pedra & 31,8 & 26,5 & $86,3 \%$ \\
Ferrari & 30,7 & 17,0 & $61,5 \%$ \\
Iracema & 22,0 & 13,3 & $63,5 \%$ \\
Santa Maria & 21,6 & 13,4 & $49,1 \%$ \\
Ester & 17,5 & 11,4 & $51,8 \%$ \\
Alto Mogiana & 16,2 & 5,5 & $70,1 \%$ \\
Moreno & 8,9 & 5,9 & $53,5 \%$ \\
São Manuel & 5,9 & 3,8 & $47,3 \%$ \\
Batatais & 5,8 & 3,0 & $46,9 \%$ \\
Vista Alegre & 4,4 & 4,9 & $24,5 \%$ \\
Unialco & 4,1 & 1,8 & $23,2 \%$ \\
Diana & 3,5 & 2,1 & $12,1 \%$ \\
Média & 20,2 & 11,6 & $57,1 \%$ \\
Mediana & 17,5 & 11,4 & $53,5 \%$ \\
Tercil 1 & $3,5-5,9$ & $1,8-4,9$ & $12,1 \%-47,3 \%$ \\
Tercil 2 & $8,9-22$ & $5,5-13,4$ & $49,1 \%-63,5 \%$ \\
Tercil 3 & $30,7-49,3$ & $17-26,6$ & $70,1 \%-96,3 \%$ \\
\hline
\end{tabular}

Fonte: Resultados da pesquisa.

Como é possível perceber, das 15 usinas investigadas, 13 possuem indicadores nos mesmos tercis, demonstrando que há uma relação importante entre produção/área e o indicador de eficiência. As quatro usinas com melhores desempenhos na produção de açúcar e etanol por área estão no agrupamento das usinas mais eficientes. Em contrapartida, as cinco usinas de piores desempenhos na produção por área (de açúcar e etanol) são, também, aquelas que se encontram no agrupamento de menor eficiência.

\subsubsection{Abordagem social}

No modelo social, a base da investigação de maximização da relação output/input foi mantida, mudando apenas o valor referência do output para o salário médio do trabalhador 
do culttivo de cana-de-açúcar. Assim sendo, procurou-se otimizar a relação salário médio por hectare plantado. O salário, corrigido para o ano base de 2007, foi utilizado como instrumento de avaliação do desempenho social das usinas, pois compõe o maior montante dos benefícios que o trabalhador recebe. A tabela 7 apresenta os resultados gerais do modelo social.

A média geral de eficiência foi de 61,5\%, com desvio-padrão de 20,2\%. Desagregando em porte, percebe-se que as usinas pequenas e grandes obtiveram os melhores resultados médios, com $66,1 \%$ e 65,1\%, respectivamente, enquanto as de médio porte registraram eficiência média social de $53,1 \%$. Os desvios-padrões não demonstraram diferenças significativas, não indicando nenhuma tendência devido ao porte.

Tabela 7 - Eficiência social das usinas

\begin{tabular}{|c|c|c|c|c|c|c|c|c|c|c|c|}
\hline Usina & 2007 & 2008 & 2009 & 2010 & 2011 & 2012 & 2013 & 2014 & 2015 & 2016 & Média \\
\hline Alto Mogiana & $46,6 \%$ & $53,1 \%$ & $51,2 \%$ & $51,5 \%$ & $51,4 \%$ & $49,0 \%$ & $52,9 \%$ & $56,8 \%$ & $53,8 \%$ & $56,4 \%$ & $52,3 \%$ \\
\hline Batatais & $21,5 \%$ & $25,5 \%$ & $30,6 \%$ & $32,8 \%$ & $36,0 \%$ & $35,0 \%$ & $39,3 \%$ & $29,7 \%$ & $41,6 \%$ & $45,0 \%$ & $33,7 \%$ \\
\hline Colombo & $53,5 \%$ & $49,4 \%$ & $54,0 \%$ & $59,7 \%$ & $61,0 \%$ & $65,5 \%$ & $69,4 \%$ & $69,5 \%$ & $61,2 \%$ & $72,9 \%$ & $61,6 \%$ \\
\hline Da Pedra & $72,6 \%$ & $74,3 \%$ & $92,3 \%$ & $91,1 \%$ & $86,1 \%$ & $99,0 \%$ & $99,2 \%$ & $98,6 \%$ & $93,3 \%$ & $98,5 \%$ & $90,5 \%$ \\
\hline Diana & $68,2 \%$ & $66,1 \%$ & $69,7 \%$ & $63,3 \%$ & $75,0 \%$ & $79,7 \%$ & $84,9 \%$ & $89,9 \%$ & $85,3 \%$ & $93,3 \%$ & $77,5 \%$ \\
\hline Ester & $52,5 \%$ & $46,6 \%$ & $52,8 \%$ & $52,5 \%$ & $70,0 \%$ & $97,2 \%$ & $58,1 \%$ & $69,4 \%$ & $76,4 \%$ & $70,7 \%$ & $64,6 \%$ \\
\hline Ferrari & $22,1 \%$ & $40,6 \%$ & $49,9 \%$ & $43,9 \%$ & $50,9 \%$ & $61,4 \%$ & $60,0 \%$ & $40,9 \%$ & $50,4 \%$ & $54,8 \%$ & $47,5 \%$ \\
\hline Iracema & $45,6 \%$ & $65,1 \%$ & $68,4 \%$ & $63,2 \%$ & $59,2 \%$ & $76,3 \%$ & $78,9 \%$ & $62,8 \%$ & $69,3 \%$ & $61,5 \%$ & $65,0 \%$ \\
\hline Moreno & $54,8 \%$ & $52,3 \%$ & $57,8 \%$ & $65,4 \%$ & $82,1 \%$ & $43,7 \%$ & $72,9 \%$ & $71,4 \%$ & $70,5 \%$ & $74,5 \%$ & $64,5 \%$ \\
\hline Nardini & $37,0 \%$ & $35,2 \%$ & $64,9 \%$ & $63,5 \%$ & $52,3 \%$ & $72,3 \%$ & $79,6 \%$ & $72,4 \%$ & $76,6 \%$ & $81,0 \%$ & $63,5 \%$ \\
\hline Santa Maria & $74,3 \%$ & $77,9 \%$ & $84,4 \%$ & $90,3 \%$ & $89,8 \%$ & $93,1 \%$ & $100,0 \%$ & $97,1 \%$ & $96,4 \%$ & $92,9 \%$ & $89,6 \%$ \\
\hline São Manuel & $36,0 \%$ & $20,3 \%$ & $32,4 \%$ & $35,4 \%$ & $35,6 \%$ & $39,1 \%$ & $44,1 \%$ & $46,9 \%$ & $46,9 \%$ & $53,0 \%$ & $39,0 \%$ \\
\hline São Martinho & $27,1 \%$ & $31,8 \%$ & $31,5 \%$ & $33,9 \%$ & $35,0 \%$ & $76,0 \%$ & $88,9 \%$ & $91,0 \%$ & $76,1 \%$ & $71,9 \%$ & $56,3 \%$ \\
\hline Unialco & $28,5 \%$ & $44,6 \%$ & $28,2 \%$ & $32,8 \%$ & $49,6 \%$ & $53,1 \%$ & $61,2 \%$ & $72,9 \%$ & $50,1 \%$ & $57,4 \%$ & $47,8 \%$ \\
\hline Vista Alegre & $43,9 \%$ & $51,4 \%$ & $50,7 \%$ & $63,1 \%$ & $65,4 \%$ & $73,6 \%$ & $79,4 \%$ & $82,6 \%$ & $92,0 \%$ & $92,6 \%$ & $69,5 \%$ \\
\hline \multicolumn{12}{|c|}{ Medidas estatísticas } \\
\hline Máximo & \multicolumn{2}{|r|}{ Mínimo } & \multicolumn{3}{|c|}{ Média } & \multicolumn{3}{|c|}{ Mediana } & \multicolumn{3}{|c|}{ Desvio-padrão } \\
\hline $100 \%$ & \multicolumn{2}{|r|}{$20,3 \%$} & \multicolumn{3}{|c|}{$61,5 \%$} & \multicolumn{3}{|c|}{$61,2 \%$} & \multicolumn{3}{|c|}{$20,2 \%$} \\
\hline
\end{tabular}

Fonte: Resultados da pesquisa.

No entanto, quando a análise é por perfil, percebe-se que as usinas de perfil etanol obtiveram melhor desempenho social, com maior homogeneidade entre a totalidade das usinas. Ainda assim, a Usina Santa Maria, de pequeno porte e perfil açúcar, ranqueou como uma das unidades de referência nessa análise. Com média geral de $89,6 \%$ e desvio-padrão de $7,9 \%$, a unidade remunerou, na média de todo o período, $\mathrm{R} \$ 0,36 /$ hectare plantado (Tabela 8), demonstrando que é possível ser socialmente eficiente, mesmo tendo porte pequeno.

Em conclusão, a tabela 8 apresenta os valores médios, do período de 2007 à 2016, de salário por área e da eficiência para cada usina.

Assim como ocorreu no modelo econômico, a variável de input "área plantada" foi selecionada para a análise, apresentada a seguir, por possuir a maior comunalidade no modelo social, como demonstrada na tabela 1. No entanto, é importante resssaltar que, além desse input, também foi utilizada como recurso produtivo a quantidade de funcionários.

Os dados dos dois indicadores apresentados (salário/área e eficiência), por usina, foram subdividos em tercis. Das 15 usinas investigadas, 8 possuem indicadores nos mesmos tercis, demonstrando que há uma razoável relação entre salário/área e o indicador de eficiência. As duas usinas com melhores desempenho na remuneração por hectare estão no agrupamento das usinas mais eficientes, sendo uma usina de pequeno porte e uma de grande porte. As 
Tabela 8 - Relações Output/Input das usinas e indicadores de eficiência

\begin{tabular}{ccc} 
Usina & Salário/área & Eficiência Social \\
Santa Maria & 0,360 & $89,6 \%$ \\
Da Pedra & 0,175 & $90,5 \%$ \\
Nardini & 0,130 & $63,5 \%$ \\
Ferrari & 0,125 & $47,5 \%$ \\
Ester & 0,112 & $64,6 \%$ \\
Colombo & 0,098 & $61,6 \%$ \\
Iracema & 0,091 & $65,0 \%$ \\
Vista Alegre & 0,078 & $69,5 \%$ \\
Diana & 0,064 & $77,5 \%$ \\
São Martinho & 0,046 & $56,3 \%$ \\
Moreno & 0,035 & $64,5 \%$ \\
Alto Mogiana & 0,029 & $52,3 \%$ \\
Unialco & 0,021 & $47,8 \%$ \\
São Manuel & 0,020 & $39,0 \%$ \\
Batatais & 0,015 & $33,7 \%$ \\
Média & 0,093 & $61,5 \%$ \\
Mediana & 0,078 & $63,5 \%$ \\
Tercil 1 & $0,015-0,035$ & $33,7 \%-52,3 \%$ \\
Tercil 2 & $0,046-0,098$ & $56,3 \%-64,6 \%$ \\
Tercil 3 & $0,112-0,36$ & $65 \%-90,5 \%$ \\
\hline
\end{tabular}

Fonte: Resultados da pesquisa.

duas usinas com piores desempenho na relação salário/área são aquelas que se encontram no agrupamento de menor eficiência, sendo as duas de médio porte.

\subsubsection{Abordagem ambiental}

Nesta análise, pretende-se entender quais usinas possuem melhor desempenho ambiental, no quesito emissão de gás carbônico. Para tanto, como já mencionado, foram extraídos dados do Projeto Canasaat/INPE, referentes à porcentagem da colheita realizada com e sem o uso de queimadas para cada usina-município investigado. Obteve-se, assim, o valor exato, em hectares, de cana colhida com maquinário e com uso de queimada, para cada usina-município analisado.

Nessa abordagem, quanto menor o valor de $\mathrm{CO}_{2}$ emitido por área plantada, em hectares, maior tenderá a ser a eficiência ambiental da usina analisada. Ressalta-se que, com a manipulação

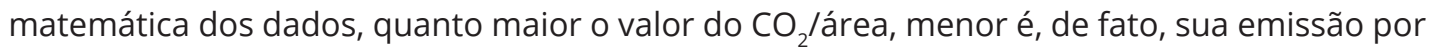
área plantada (em hectares), resultando em maior eficiência ambiental. A tabela 9 demonstra o resultado geral do modelo.

A média de eficiência ambiental foi de 54,8\%, com desvio-padrão de 30\%. Na análise por porte, as usinas pequenas pontuaram melhores índices de eficiência que as grandes e médias, porém registrou-se significativa heterogeneidade nos desvios-padrões, não possibilitando traçar linha de tendência quanto ao porte. Entretanto, na análise por perfil, notou-se a tendência de que as usinas de etanol obtiveram maior média de eficiência, com menor desvio-padrão, demonstrando homogeneidade e eficiência.

Novamente, a Usina Santa Maria, do grupo J. Pilon, obteve destaque. A usina teve média de eficiência ambiental de 96,3\%, e foi a que registrou menor emissão de $\mathrm{CO}_{2}$, em 2013. Ela registrou média de emissão de $3,8 E^{-8}$ para os anos analisados - contra média de $8,2 E^{-9}$ 
Tabela 9 - Eficiência ambiental das usinas

\begin{tabular}{|c|c|c|c|c|c|c|c|c|}
\hline Usina & 2007 & 2008 & 2009 & 2010 & 2011 & 2012 & 2013 & Média \\
\hline Alto Mogiana & $26,4 \%$ & $31,6 \%$ & $32,7 \%$ & $36,1 \%$ & $30,4 \%$ & $35,7 \%$ & $32,7 \%$ & $32,2 \%$ \\
\hline Batatais & $3,6 \%$ & $4,5 \%$ & $3,7 \%$ & $8,1 \%$ & $10,3 \%$ & $4,9 \%$ & $13,6 \%$ & $6,9 \%$ \\
\hline Colombo & $55,3 \%$ & $53,2 \%$ & $52,9 \%$ & $55,8 \%$ & $54,7 \%$ & $57,5 \%$ & $62,0 \%$ & $55,9 \%$ \\
\hline Da Pedra & $63,3 \%$ & $64,4 \%$ & $67,4 \%$ & $78,3 \%$ & $70,6 \%$ & $76,3 \%$ & $81,2 \%$ & $71,6 \%$ \\
\hline Diana & $53,5 \%$ & $42,6 \%$ & $48,6 \%$ & $46,5 \%$ & $36,6 \%$ & $39,2 \%$ & $41,8 \%$ & $44,1 \%$ \\
\hline Ester & $73,7 \%$ & $77,3 \%$ & $94,0 \%$ & $81,7 \%$ & $65,4 \%$ & $87,8 \%$ & $87,7 \%$ & $81,1 \%$ \\
\hline Ferrari & $65,3 \%$ & $84,1 \%$ & $73,9 \%$ & $84,8 \%$ & $72,1 \%$ & $72,1 \%$ & $72,7 \%$ & $75,0 \%$ \\
\hline Iracema & $72,3 \%$ & $79,3 \%$ & $74,3 \%$ & $86,9 \%$ & $78,9 \%$ & $80,9 \%$ & $85,0 \%$ & $79,7 \%$ \\
\hline Moreno & $27,2 \%$ & $28,3 \%$ & $28,9 \%$ & $30,7 \%$ & $25,5 \%$ & $5,5 \%$ & $34,4 \%$ & $25,8 \%$ \\
\hline Nardini & $98,2 \%$ & $96,0 \%$ & $98,4 \%$ & $97,3 \%$ & $92,2 \%$ & $97,0 \%$ & $98,4 \%$ & $96,8 \%$ \\
\hline Santa Maria & $99,2 \%$ & $92,7 \%$ & $93,6 \%$ & $95,3 \%$ & $95,6 \%$ & $97,5 \%$ & $100,0 \%$ & $96,3 \%$ \\
\hline São Manuel & $15,9 \%$ & $3,4 \%$ & $20,6 \%$ & $20,8 \%$ & $15,9 \%$ & $20,6 \%$ & $20,0 \%$ & $16,7 \%$ \\
\hline São Martinho & $69,0 \%$ & $72,7 \%$ & $73,5 \%$ & $73,0 \%$ & $69,0 \%$ & $70,8 \%$ & $74,3 \%$ & $71,7 \%$ \\
\hline Unialco & $4,0 \%$ & $16,9 \%$ & $4,5 \%$ & $11,6 \%$ & $19,0 \%$ & $3,6 \%$ & $17,2 \%$ & $11,0 \%$ \\
\hline Vista Alegre & $68,1 \%$ & $57,7 \%$ & $58,5 \%$ & $53,8 \%$ & $52,7 \%$ & $48,4 \%$ & $56,7 \%$ & $56,6 \%$ \\
\hline \multicolumn{9}{|c|}{ Medidas estatísticas } \\
\hline Máximo & Mínimo & \multicolumn{2}{|c|}{ Média } & \multicolumn{2}{|c|}{ Mediana } & \multicolumn{3}{|c|}{ Desvio-padrão } \\
\hline $100 \%$ & $3,4 \%$ & \multicolumn{2}{|c|}{$54,8 \%$} & \multicolumn{2}{|c|}{$57,7 \%$} & \multicolumn{3}{|c|}{$30 \%$} \\
\hline
\end{tabular}

Fonte: Resultados da pesquisa.

de todas as usinas e $1,2 E^{-8}$ das usinas pequenas. Comprova-se, novamente, que uma usina de pequeno porte pode obter altos índices de eficiência ambiental, assim como social, sem necessitar de economias de escala ou grandeza de operação.

A tabela 10 aponta a relação existente entre as emissões de $\mathrm{CO}_{2}$ e o indicador eficiência ambiental. Quanto maior o valor do indicador $\mathrm{CO}_{2} / a ́ r e a$, menor será o montante de $\mathrm{CO}_{2}$ expelido por usina por hectare plantado - devido à transformação monotônica decrescente de Seiford \& Zhu (2002), utilizada no tratamento dos dados das emissões - e, por assim ser, maior deverá ser sua eficiência ambiental, pois significa que tal unidade produtiva está emitindo menos $\mathrm{CO}_{2}$ por área plantada, maximizando assim sua eficiência ambiental por hectare de plantio de cana-de-açúcar.

Da mesma forma que ocorreu nos modelos econômico e social, a variável de input "área plantada" foi selecionada para a análise, apresentada a seguir, por possuir a maior comunalidade no modelo ambiental (demonstrada na tabela 1). Os dados dos dois indicadores apresentados ( $\mathrm{CO}_{2} /$ área e eficiência), por usina, foram subdividos em tercis.

Tabela 10 - Relações Output/Input das usinas e indicadores de eficiência

\begin{tabular}{ccc} 
Usina & $\mathbf{C O}_{2} /$ área & Eficiência Ambiental \\
Santa Maria & $3,8 \mathrm{E}-08$ & $96,3 \%$ \\
Nardini & $2,3 \mathrm{E}-08$ & $96,8 \%$ \\
Ferrari & $1,4 \mathrm{E}-08$ & $75,0 \%$ \\
Ester & $1,3 \mathrm{E}-08$ & $81,1 \%$ \\
Da Pedra & $9,0 \mathrm{E}-09$ & $71,6 \%$ \\
Iracema & $8,5 \mathrm{E}-09$ & $79,7 \%$ \\
Colombo & $5,5 \mathrm{E}-09$ & $55,9 \%$ \\
Vista Alegre & $4,4 \mathrm{E}-09$ & $56,6 \%$ \\
\hline
\end{tabular}

Fonte: Resultados da pesquisa. 
Tabela 10 - Continuação...

\begin{tabular}{ccc} 
Usina & CO $_{2} /$ área & Eficiência Ambiental \\
São Martinho & $4,3 \mathrm{E}-09$ & $71,8 \%$ \\
Diana & $1,4 \mathrm{E}-09$ & $44,1 \%$ \\
Alto Mogiana & $7,0 \mathrm{E}-10$ & $32,2 \%$ \\
Moreno & $6,5 \mathrm{E}-10$ & $25,8 \%$ \\
São Manuel & $3,8 \mathrm{E}-10$ & $16,7 \%$ \\
Unialco & $3,2 \mathrm{E}-10$ & $11,0 \%$ \\
Batatais & $2,3 \mathrm{E}-10$ & $7,0 \%$ \\
Média & $8,2 \mathrm{E}-09$ & $54,8 \%$ \\
Mediana & $4,4 \mathrm{E}-09$ & $56,6 \%$ \\
Tercil 1 & $0,015-0,035$ & $7 \%-32,2 \%$ \\
Tercil 2 & $0,046-0,098$ & $44,1 \%-71,8 \%$ \\
Tercil 3 & $0,112-0,36$ & $75 \%-96,8 \%$ \\
\hline
\end{tabular}

Fonte: Resultados da pesquisa.

Das 15 usinas investigadas, 13 possuem indicadores nos mesmos tercis, demonstrando que há uma relação muito importante entre emissão de $\mathrm{CO}_{2}$ /área e o indicador de eficiência. As quatro usinas com melhores desempenhos na emissão de $\mathrm{CO}_{2}$ por hectare estão no agrupamento das usinas mais eficientes (três usinas de pequeno porte e uma de médio porte). As cinco usinas com piores desempenhos na relação $\mathrm{CO}_{2}$ /área localizam-se no agrupamento de menor eficiência, sendo uma de grande porte, três de médio porte e uma de pequeno porte.

\subsubsection{Abordagem sustentável}

Nessa análise, o intuito é utilizar todos os outputs usados anteriormente, mantendo os inputs já especificados. O objetivo primordial é delimitar usinas sustentáveis nos quesitos econômico, social e ambiental, conjuntamente. Essa análise foi realizada até o ano de 2013, devido à indisponibilidade de dados referentes à emissão de $\mathrm{CO}_{2}$ para as usinas-municípios analisados em períodos posteriores. A tabela 11 demonstra os resultados gerais da abordagem sustentável.

Tabela 11 - Eficiência sustentável das usinas

\begin{tabular}{ccccccccc} 
Usina & $\mathbf{2 0 0 7}$ & $\mathbf{2 0 0 8}$ & $\mathbf{2 0 0 9}$ & $\mathbf{2 0 1 0}$ & $\mathbf{2 0 1 1}$ & $\mathbf{2 0 1 2}$ & $\mathbf{2 0 1 3}$ & Média \\
\hline Alto Mogiana & $\mathbf{3 7 , 8} \%$ & $\mathbf{4 9 , 1} \%$ & $62,8 \%$ & $58,1 \%$ & $65,3 \%$ & $51,2 \%$ & $55,5 \%$ & $54,3 \%$ \\
Batatais & $\mathbf{3 0 , 0} \%$ & $31,3 \%$ & $33,9 \%$ & $37,8 \%$ & $42,6 \%$ & $35,1 \%$ & $41,3 \%$ & $36,0 \%$ \\
Colombo & $65,8 \%$ & $68,8 \%$ & $\mathbf{7 3 , 2} \%$ & $\mathbf{7 1 , 1} \%$ & $\mathbf{7 5 , 1} \%$ & $\mathbf{7 2 , 5} \%$ & $78,3 \%$ & $\mathbf{7 2 , 1} \%$ \\
Da Pedra & $91,8 \%$ & $86,3 \%$ & $96,6 \%$ & $96,3 \%$ & $94,6 \%$ & $98,8 \%$ & $100,0 \%$ & $94,9 \%$ \\
Diana & $47,7 \%$ & $42,3 \%$ & $42,9 \%$ & $40,6 \%$ & $48,1 \%$ & $51,2 \%$ & $57,1 \%$ & $47,1 \%$ \\
Ester & $48,0 \%$ & $45,0 \%$ & $67,3 \%$ & $49,7 \%$ & $64,8 \%$ & $91,4 \%$ & $55,2 \%$ & $60,2 \%$ \\
Ferrari & $28,6 \%$ & $51,5 \%$ & $54,9 \%$ & $56,6 \%$ & $61,4 \%$ & $64,7 \%$ & $68,2 \%$ & $55,1 \%$ \\
Iracema & $43,2 \%$ & $69,0 \%$ & $73,0 \%$ & $80,0 \%$ & $68,4 \%$ & $76,3 \%$ & $80,5 \%$ & $70,1 \%$ \\
Moreno & $54,0 \%$ & $46,9 \%$ & $64,7 \%$ & $94,3 \%$ & $79,9 \%$ & $53,0 \%$ & $74,5 \%$ & $66,7 \%$ \\
Nardini & $65,0 \%$ & $65,0 \%$ & $71,1 \%$ & $78,7 \%$ & $76,5 \%$ & $76,4 \%$ & $82,4 \%$ & $73,6 \%$ \\
Santa Maria & $84,5 \%$ & $76,9 \%$ & $85,8 \%$ & $86,5 \%$ & $90,2 \%$ & $94,6 \%$ & $96,5 \%$ & $87,9 \%$ \\
São Manuel & $30,4 \%$ & $27,7 \%$ & $41,7 \%$ & $42,4 \%$ & $40,5 \%$ & $40,5 \%$ & $44,5 \%$ & $38,2 \%$ \\
São Martinho & $65,0 \%$ & $62,9 \%$ & $69,5 \%$ & $65,0 \%$ & $63,8 \%$ & $86,4 \%$ & $94,7 \%$ & $72,5 \%$ \\
Unialco & $34,5 \%$ & $37,3 \%$ & $35,0 \%$ & $34,4 \%$ & $40,0 \%$ & $40,9 \%$ & $39,9 \%$ & $37,4 \%$ \\
\hline
\end{tabular}

Fonte: Resultados da pesquisa. 
Tabela 11 - Continuação...

\begin{tabular}{ccccccccc} 
Usina & $\mathbf{2 0 0 7}$ & $\mathbf{2 0 0 8}$ & $\mathbf{2 0 0 9}$ & $\mathbf{2 0 1 0}$ & $\mathbf{2 0 1 1}$ & $\mathbf{2 0 1 2}$ & $\mathbf{2 0 1 3}$ & Média \\
\hline Vista Alegre & $29,9 \%$ & $35,8 \%$ & $34,0 \%$ & $41,0 \%$ & $51,4 \%$ & $53,4 \%$ & $66,0 \%$ & $44,5 \%$ \\
\hline Máximo & Mínimo & Média & Mediana & \multicolumn{2}{c}{ Desvio-padrão } \\
\hline $100 \%$ & $27,7 \%$ & & $60,7 \%$ & $62,8 \%$ & $20,0 \%$ \\
\hline
\end{tabular}

Fonte: Resultados da pesquisa.

A eficiência média das usinas foi de $60,7 \%$, com desvio-padrão de $20 \%$. Na análise por porte, percebe-se um melhor desempenho sustentável das usinas grandes, enquanto há uniformidade entre as de médio e pequeno porte. Por sua vez, para a análise de usinas por perfil, conclui-se que há uma tendência de usinas de perfil etanol possuírem melhor desempenho sustentável que as usinas de perfil açúcar, embora de maneira menos uniforme.

É importante destacar os desempenhos das usinas Da Pedra e Santa Maria na ótica sustentável. A primeira, de porte grande e perfil etanol, obteve média de eficiência sustentável de $94,9 \%$, com valor máximo, em 2013, de 100\%, sendo a usina mais sustentável da amostra. Um dos motivos para isso é que a unidade é atuante do Protocolo Agroambiental Etanol Mais Verde e certificado pela Bonsucro $^{T M} \mathrm{EU}$, que garante os padrões de sustentabilidade exigidos internacionalmente, assim como aderiu ao Programa RenovaBio.

De forma igualmente importante, a Usina Santa Maria também demonstrou ser altamente sustentável, com eficiência de 96,5\%, no ano de 2013 - mesmo ano em que ela foi a mais eficiente tanto social quanto ambientalmente. Mais uma vez, comprova-se que não há necessidade de economias de escala e grandeza de operação para ser eficiente nas óticas propostas por este trabalho.

Finalmente, a tabela 12 resume os resultados dos indicadores utilizados na análise sustentável e seus respectivos indicadores de eficiência sustentável.

Tabela 12- Relações Output/Input das usinas e indicadores de eficiência

\begin{tabular}{cccccc} 
Usina & Açúcar/área & Etanol/área & Salário/área & CO2/área & Eficiência \\
Colombo & 41,2 & 17,3 & 0,098 & $5,5 \mathrm{E}-09$ & $72,1 \%$ \\
Da Pedra & 31,8 & 26,5 & 0,175 & $9,0 \mathrm{E}-09$ & $94,9 \%$ \\
Ferrari & 30,7 & 17,0 & 0,125 & $1,4 \mathrm{E}-08$ & $55,1 \%$ \\
Iracema & 22,0 & 13,3 & 0,091 & $8,5 \mathrm{E}-09$ & $70,1 \%$ \\
Santa Maria & 21,6 & 13,4 & 0,360 & $3,8 \mathrm{E}-08$ & $87,9 \%$ \\
Ester & 17,5 & 11,4 & 0,112 & $1,3 \mathrm{E}-08$ & $60,2 \%$ \\
Alto Mogiana & 16,2 & 5,5 & 0,029 & $7,0 \mathrm{E}-10$ & $54,3 \%$ \\
Nardini & 49,3 & 26,6 & 0,130 & $2,3 \mathrm{E}-08$ & $73,6 \%$ \\
São Martinho & 39,9 & 20,7 & 0,046 & $4,3 \mathrm{E}-09$ & $72,5 \%$ \\
Moreno & 8,9 & 5,9 & 0,035 & $6,5 \mathrm{E}-10$ & $66,7 \%$ \\
São Manuel & 5,9 & 3,8 & 0,020 & $3,8 \mathrm{E}-10$ & $38,2 \%$ \\
Batatais & 5,8 & 3,0 & 0,015 & $2,3 \mathrm{E}-10$ & $36,0 \%$ \\
Vista Alegre & 4,4 & 4,9 & 0,078 & $4,4 \mathrm{E}-09$ & $44,5 \%$ \\
Unialco & 4,1 & 1,8 & 0,021 & $3,2 \mathrm{E}-10$ & $37,4 \%$ \\
Diana & 3,5 & 2,1 & 0,064 & $1,4 \mathrm{E}-09$ & $47,1 \%$ \\
Média & 20,2 & 11,6 & 0,093 & $8,2 \mathrm{E}-09$ & $60,7 \%$ \\
Mediana & 17,5 & 11,4 & 0,078 & $4,4 \mathrm{E}-09$ & $60,2 \%$ \\
Tercil 1 & $3,5-5,9$ & $1,8-4,9$ & $0,015-0,035$ & $0,015-0,035$ & $36 \%-47,1 \%$ \\
\hline
\end{tabular}

Fonte: Resultados da pesquisa. 
Tabela 12- Continuação...

\begin{tabular}{cccccc} 
Usina & Açúcar/área & Etanol/área & \multicolumn{1}{c}{ Salário/área } & \multicolumn{1}{c}{ CO2/área } & \multicolumn{1}{c}{ Eficiência } \\
Tercil 2 & $8,9-22$ & $5,5-13,4$ & $0,046-0,098$ & $0,046-0,098$ & $54,3 \%-70,1 \%$ \\
Tercil 3 & $30,7-49,3$ & $17-26,6$ & $0,112-0,36$ & $0,112-0,36$ & $72,1 \%-94,9 \%$ \\
\hline
\end{tabular}

Fonte: Resultados da pesquisa.

O intuito do modelo sustentável é explanar a lógica de que uma usina será sustentável se ela for econômico, social e ambientalmente sustentável. Das 15 usinas investigadas, apenas 6 possuem indicadores nos mesmos tercis. As usinas Da Pedra e Nardini, de grande e médio porte, respectivamente, apresentaram bons indicadores de produção, emissão de $\mathrm{CO}_{2}$ e remuneração por área e, consequentemente, seus índices de eficiência estão localizados no terceiro tercil. Três outras usinas, São Manuel, Batatais e Unialco (sendo as duas primeiras de porte médio e a terceira de pequeno porte), todas de perfil açúcar, apresentaram baixos indicadores de produtividade, $\mathrm{CO}_{2}$ e salário por área e obtiveram baixos índices de eficiência. No quadrante intermediário dos indicadores de produtividade/área e de eficiência (segundo tercil), apenas a usina Iracema, de médio porte e perfil açúcar, se enquadrou.

Para alcançar a eficiência sustentável, é necessário que a usina apresente bons indicadores econômico, social e ambiental. Essa exigência torna mais complexa a tarefa de obtenção de um bom indicador de eficiência, o que explica o fato de $40 \%$ das usinas investigadas possuírem indicadores nos mesmos tercis.

\section{Considerações Finais}

O presente estudo teve como objetivo analisar a eficiência de quinze usinas de cana-de-açúcar paulistas, produtoras de açúcar e etanol, no período de 2007 a 2016, sob as óticas econômica, social, ambiental e sustentável. Para tanto, utilizou a metodologia Análise Envoltória de Dados, com orientação output e retornos variáveis de escala.

Com as usinas classificadas em porte e perfil, os resultados obtidos condizem com a realidade da atividade sucroalcooleira paulista. As usinas grandes demonstraram melhor eficiência e homogeneidade nas óticas econômica e sustentável, indicando incidência de economias de escala e de melhores práticas sustentáveis por porte. As usinas de pequeno porte registraram melhores desempenhos nas óticas social e ambiental, com valores intermediários de desvio-padrão. Por sua vez, as usinas médias não ranquearam eficientes nas análises, registrando desvio-padrão irregular para todos os modelos.

$\mathrm{Na}$ análise por perfil, nota-se melhor desempenho das usinas de perfil etanol nas óticas social, ambiental e sustentável. Tais usinas foram mais homogêneas nas abordagens social e ambiental, indicando tendência de melhor desempenho, em termos de eficiência e regularidade, nestas óticas. As usinas de perfil açúcar, no entanto, foram mais eficientes na abordagem econômica, assim como mais homogêneas, sugerindo melhor eficiência e uniformidade das usinas de core product açúcar para com o viés econômico.

O resultado do modelo sustentável deve ser mais bem discutido. A tendência observada foi de que as usinas que tiveram os melhores indicadores nas óticas econômica, social e ambiental foram aquelas que registraram maiores escores de eficiência sustentável. O caso supracitado da Usina da Pedra e da Usina Santa Maria, ambas com ótimos resultados das abordagens analisadas por este artigo, comprova tal tendência.

Nesse sentido, o trabalho tem caráter inovador, por criar um modelo sustentável aplicável à agroindústria sucroenergética, algo não realizado por nenhuma outra pesquisa, nacional e internacional, para um período significativo de tempo: 2007 a 2016. Portanto, buscou-se 
preencher tal lacuna na literatura, enfatizando um número significativo de usinas e tempo, além de considerar abordagens relevantes para o atual estágio do sistema capitalista.

Por fim, expõem-se as limitações encontradas no decorrer da pesquisa, assim como sugestões para futuros trabalhos. A irregularidade de dados no Anuário da Cana foi fator de complicação, superado por filtragem maior das unidades analisadas. Outra questão importante diz respeito aos modelos utilizados. Como todo modelo, os modelos aqui adotados não são perfeitos e explicaram parte considerável da variabilidade dos outputs, mas não explicaram a totalidade. Os dados para o setor investigado são limitados e nem sempre padronizados, o que dificultou o uso de outras variáveis que poderiam tornar os modelos mais robustos. Por fim, em relação ao modelo social, os dados relativos à quantidade de funcionários se mostraram bastante dispersos, por usinas, no horizonte temporal da pesquisa, o que pode justificar o fato de $46 \%$ das usinas não possuírem indicadores nos mesmos tercis.

Para futuras pesquisas, sugere-se o uso de variáveis como (i) produção de energia, a partir da biomassa da cana-de-açúcar, (ii) benefícios sociais aos colaboradores de cana usina e (iii) práticas agroecológicas e uso de produtos orgânicos no cultivo da cana-de-açúcar.

\section{Referências}

Adler, N., \& Golany, B. (2001). Evaluation of deregulated airline networks using data envelopment analysis combined with principle component analysis with an application to Western Europe. European Journal of Operational Research, 132, 260-273.

Adler, N., \& Yazhemsky, E. (2010). Improving discrimination in data envelopment analysis: PCA-DEA or variable reduction. European Journal of Operational Research, 202, 273-284.

Agência Embrapa de Informação Tecnológica - Ageitec. (2006). Base de dados técnicos de produção agrícola. Recuperado em 15 de dezembro de 2019, de http://www.agencia. cnptia.embrapa.br/gestor/canadeacucar/arvore/CONTAG01_109_22122006154841.html

Banker, R. D., Chang, H., \& Cooper, W. W. (1996). Equivalence and implementation of alternative methods for determining returns to scale in data envelopment analysis. European Journal of Operational Research, 89(3), 473-481.

Banker, R. D., Charnes, A., \& Cooper, W.W. (1984). Some models for estimating technical and scale inefficiencies in data envelopment analysis. Management Science, 30, 1078-1092.

Brasil. Ministério da Agricultura, Pecuária e Abastecimento - Mapa. (2018). Sistema de Acompanhamento de Produção Canavieira - SAPCANA. Recuperado em 15 de dezembro de 2019, de http://sistemasweb.agricultura.gov.br/pages/SAPCANA.html

Brasil. Ministério da Economia. (2019). Relação Anual de Informações Sociais (RAIS). Base de dados estatísticos RAIS e CAGED. Recuperado em 15 de dezembro de 2019, de http:// bi.mte.gov.br/bgcaged/rais.php.

Brunozi Junior, A. C.; Abrantes, L. A.; Gomes, A. P.; Gonçalves, R. M. L. (2012). Eficiência produtiva e análise financeira de usinas de cana-de-açúcar do Estado de São Paulo. Revista Ambiente Contábil, 4(2), 74-92.

Cano, A., \& Tupy, O. (2005). Eficiência produtiva de usinas de açúcar e álcool do estado de São Paulo. Anais do XLIII Congresso da Sober, Ribeirão Preto: Sociedade Brasileira de Economia e Sociologia Rural. 
Figueiredo, E. B., \& Scala, N. (2011). Greenhouse gas balance due to the conversion of sugarcane areas from burned to green harvest in Brazil. Agriculture Ecosystems \& Environment, Amsterdam, 141(1-2), 77-85.

Goldemberg, J., Coelho, S. T., \& Guardabassi, P. (2008). The sustainability of ethanol production from sugarcane. Energy Policy, 36, 86-97.

Hassini, E., Surti, C., \& Searcy, C. (2012). A literature review and a case study of sustainable supply chains with a focus on metrics. International Journal of Production Economics, 140(1), 69-82.

Kumar, S., \& Arora, N. (2012). Evaluation of technical in Indian sugar industry: An application of full cumulative data envelopment analysis. Eurasian Journal of Business and Economics, 5(9), 57-78.

Macedo, M. A. S., Cípola, F. C. F., \& Ferreira, A. F. R. (2010). Desempenho social no agronegócio brasileiro: aplicando DEA no segmento de usinas de processamento de cana-de-açúcar. Revista de Economia e Sociologia Rural, 48(1), 223-243.

Nataraja, N. R., \& Johnson, A. L. (2011). Guideline for using variable selections techniques in data envelopment analysis. European Journal of Operational Research, 215, 662-669.

Nova Cana (2012). Periódico informativo sobre o setor sucroenergético. Recuperado em 15 de dezembro de 2019, de https://www.novacana.com/etanol/curiosidades

Pereira, C. N., \& Silveira, J. M. F. J. (2016). Análise exploratória da eficiência produtiva das usinas de cana-de-açúcar na região centro-sul do Brasil. Revista de Economia e Sociologia Rural, 54(1), 147-166.

Salgado Junior, A. P., Bonacim, C. A. G., \& Pacagnella Junior, A. P. (2009). Aplicação da Análise Envoltória de Dados (DEA) para avaliação de eficiência de usinas de açúcar e álcool da região nordeste do estado de São Paulo. Organizações Rurais e Agroindustriais, 11(3), 1-20.

Seiford, L. M., \& Zhu, J. (2002). Modeling undesirable factors in efficiency evaluation. European Journal of Operational Research, 142(1), 16-20.

Singh, S. P., \& Agarwal, S. (2006). Total factor productivity growth, technical progress and efficiency change in sugar industry of Uttar Pradesh. The Indian Economic Journal, 54(2), 59-82.

Steingraber, R., \& Gonçalves, F. O. (2013). A heterogeneidade do processo de inovação da indústria brasileira: uma análise a partir dos três tipos de inovação - produto, processo e organizacional. In Anais do XLI Encontro Nacional de Economia, Foz do Iguaçu: ANPEC.

Zambianco, W. M. (2018). Avaliação do desempenho das regiões canavieiras do estado de São Paulo: uma análise de variáveis econômicas, sociais e ambientais utilizando Análise Envoltória de Dados (DEA) e Índice Malmquist DEA. (Dissertação de mestrado). Escola de Engenharia de São Carlos, Universidade de São Paulo, São Carlos. 137 p. 